\title{
Reproductive factors and risk of oesophageal cancer, a population-based nested case-control study in Sweden
}

\author{
Y Lü,1 and J Lagergren ${ }^{1,2}$ \\ 'Department of Molecular Medicine and Surgery, Upper Gastrointestinal Research, Karolinska Institutet, Stockholm, Sweden; '2King's College London, \\ Division of Cancer Studies, London, UK
}

BACKGROUND: The role of sex hormonal influence in explaining the strong male predominance in oesophageal adenocarcinoma (EA) needs attention.

METHODS: A nation-wide nested case-control study was initiated from the Swedish Multi-Generation Register with subjects born since 1932. The study exposures were the number of children and age at having the first child. Cases of EA, gastroesophageal junctional adenocarcinoma (EJA), and oesophageal squamous cell carcinoma (SCC) were identified. Ten age- and sex-matched controls were randomly selected for each case. Conditional logistic regression was used to calculate odds ratios (ORs) and 95\% confidence intervals (Cls).

RESULTS: In women, I I 5 EA, 246 EJA, and 363 SCC were identified. Comparing parous with non-parous women, a decreased risk of $E A$ was indicated $(\mathrm{OR}=0.66,95 \% \mathrm{Cl} 0.38-1.14)$, which became statistically significant when $E A$ and $E J A$ were combined $(O R=0.73$, $95 \% \mathrm{Cl}$ 0.53-0.99). All these associations were, however, at least as strong in men. Age at first birth did not show significant risk in women, but showed risk in men. In addition, the results were similar for SCC in both sexes.

CONCLUSION: These findings indicate that associations between the reproductive factors parity and age at first birth, and risk of EA might not be explained by sex hormonal influence.

British Journal of Cancer (2012) 1 07, 564-569. doi:I0.1038/bjc.2012.285 www.bjcancer.com

Published online 5 July 2012

(c) 2012 Cancer Research UK

Keywords: oesophageal adenocarcinoma; age at first birth; parity; sex hormone

The incidence of oesophageal adenocarcinoma (EA) has increased rapidly in western populations, particularly in White men (Blot et al, 1991; Botterweck et al, 2000; Lepage et al, 2008; Voutilainen, 2008; Cook et al, 2009). Sex hormonal influence has been hypothesised to be involved in the aetiology of EA and gastroesophageal junctional adenocarcinoma (EJA). However, little evidence is currently available, except for a protective effect of breastfeeding in women (Cronin-Fenton et al, 2010). Adenocarcinoma and squamous cell carcinoma (SCC) are the main histological types of oesophageal cancer, and they have different risk factor profiles. The male to female ratio $(2: 1$ to $3: 1)$ in SCC is explained by different patterns in the use of the main risk factors, alcohol and tobacco smoking, in men and women (Castellsague et al, 1999), but the 5:1 to 7:1 male predominance in EA and junctional adenocarcinoma is not fully explained by the main risk factors, gastroesophageal reflux or obesity (Lofdahl et al, 2008; Whiteman et al, 2008). Previous studies evaluating endogenous or exogenous sex hormonal factors in relation to risk of EA or junctional adenocarcinoma have been hampered by small sample sizes and have provided contradictory results (Lagergren et al, 1998, 2005; Cheng et al, 2000; Freedman et al, 2010; Bodelon et al, 2011; Green et al, 2012a). The reproductive factors parity and age at first delivery are regarded as proxies for endogenous sex hormonal exposure in women (Hankinson et al, 1995) but because of the rarity of female adenocarcinoma, few cohort studies have

*Correspondence: Dr Y Lu; E-mail: yunxia.lu@ki.se

Received 12 March 2012; revised II May 2012; accepted 30 May 2012; published online 5 July 2012 recruited more than 30 cases to examine the aetiologic role of such reproductive factors, except one recent study from the United Kingdom (Green et al, 2012b). Furthermore, the previous studies addressing reproductive factors as a proxy for sex hormonal influence did not consider men, but including an evaluation of men could provide a measure of confounding by non-hormonal factors, for example, education, socio-economic status, and lifestyle habits, which might influence the patterns of childbearing. The long history and nation-wide completeness of health registers in Sweden provide excellent opportunities for large and populationbased cohort studies with long and complete follow-up. This study used such register data to test the hypothesis that reproductive factors have a role in the aetiology of EA and junctional adenocarcinoma in women. For assessment of confounding and other biases, we also studied these exposures in men and in relation to oesophageal SCC.

\section{METHODS}

\section{Study design}

This was a population-based, Swedish nation-wide case-control study, nested within the Swedish Multi-Generation Register during the period 1 January 1932 to 31 December 2008. Subjects aged older than 15 years were included in the study cohort. The study exposures, that is, number of children and age at first childbirth, were assessed from the Multi-Generation Register. The cases comprised all cohort members with a first (no previous gastrointestinal cancer) EA, EJA, or SCC. Cases with cancer of the oesophagus 
or gastroesophageal junction diagnosed during 1960-2008 were identified from the Swedish Cancer Register. Malignancies found first at autopsy were not included. The International Classification of Diseases version seven (ICD7) codes for cancer of the oesophagus and gastroesophageal junction were ' 150 ' and '1511', respectively. The histological types were identified using $\mathrm{WHO} /$ HS/CANC/24.1 histology codes, in which the code '096' defined adenocarcinoma and '146' defined SCC. Cancer of the gastroesophageal junction was registered separately from 1970 .

For each case, 10 control subjects were randomly selected from the source cohort, and matched for sex and age (the same calendar year) of the cases. To be eligible, a control had to be alive, have to had no previous diagnosis of any gastrointestinal cancer, and no history of emigration before the date of the diagnosis of the corresponding case. The number of births was assessed up to the date of the diagnosis of cancer for cases and the corresponding date for the controls. The study endpoints were any cancer, death, emigration, or end of the study period (31 December 2008), whichever occurred first. The study was approved by the Regional Ethical Review Board in Stockholm, Sweden.

\section{Data sources}

This study was based on data collected from four nation-wide Swedish population-based registers: the Multi-Generation Register, the Cancer Register, the Register of the Total Population, and the Education Register. The personal identity number, a unique 10digit number assigned to each resident in Sweden upon birth or immigration, was used for the linkage of all participating individuals between these registers.

The Multi-Generation Register is based on index persons born in 1932 and later who have lived in Sweden since at least 1961. The parents, siblings, and children of each included individual are recorded, thus enabling retrieval of data on number of children and age at childbirths. All cohort members were included in this register.

The Swedish Cancer Register includes the date of diagnosis, site, and histological type of all malignant tumours diagnosed in Sweden since 1958. All newly diagnosed tumours in Sweden must be reported to the Cancer Register by the clinician, pathologist, or cytologist. All diagnosis codes are translated into ICD7. The Cancer Register is 98\% complete regarding oesophageal cancer (Lindblad et al, 2006), and at least $96 \%$ complete regarding all cancers (Barlow et al, 2008).

The Register of the Total Population provides $100 \%$ complete and continuously updated information on dates of birth, death, emigration, and immigration, which were used to define some study endpoints.

The Swedish Education Register provides information on highest attained educational level (years of education) for virtually all Swedish residents. This register is updated yearly.

\section{Statistical analyses}

Multivariable conditional logistic regression, conditioned on age and sex, was used to estimate odds ratios (ORs) and 95\% confidence intervals (CIs) as measures of the association between parity and age at first birth in relation to risk of oesophageal cancers. Parity and age at first birth were included in the same model to disentangle the separate effects of these variables following mutual adjustments (McKnight et al, 1999). Participants with at least one child were categorised as parous (has children for men), whereas those without any children were classified as nonparous (no children for men). Parity was further defined as the number of live births before the cohort member reached any of the endpoints, and was categorised into three groups as follows: 1, 2, or $\geqslant 3$ births. Age at first birth was categorised into three groups: $<20,20-29$, or $\geqslant 30$ years. To identify potential differences in effects in pre- and post-menopausal women, analyses were stratified into women older or younger than 50 years at diagnosis or index date, a cut-off well in agreement with the previous research (Gold et al, 2001; Rodstrom et al, 2003). Only results for subjects aged 50 years or older were reported because of the limited sample size for subjects younger than 50 years. All exposure variables were similarly categorised in male participants.

Potential confounding factors were considered in the analyses based on different causal hypothetical models for adenocarcinoma or SCC of the oesophagus or gastroesophageal junction: (1) education (categorised into $\leqslant 9,10-12$, or $\geqslant 13$ years), (2) diabetes (yes or no, yes including ICD codes: 260 in ICD-8, 250 in ICD-9, and E10-E14 in ICD-10), (3) obesity (yes or no, yes including codes 27799 in ICD-8, 278A in ICD-9, and E66 in ICD-10), (4) tobacco smoking (yes or no, yes included diagnoses known to be associated with smoking, i.e., chronic obstructive pulmonary disease or bronchitis with codes $501.99,502,527.10$, or 527.11 in ICD-7, 490-492 in ICD-9 and ICD-8, and J41-J44 in ICD-10, or atherosclerosis or peripheral vascular disease with codes 450.00 , $450.10,453.33$ in ICD-7, 440, 443.90 or 445 in ICD-8, 440, $443 \mathrm{X}$ in ICD-9, and I70, I73.9 in ICD-10), and (5) alcohol abuse (yes or no, yes including diagnoses known to be associated with overconsumption of alcohol, i.e., alcohol-related liver disease with codes 581.10 or 583.10 in ICD-7, 571.00 or 571.01 in ICD-8, 571.A or 571.C in ICD-9, and K70 in ICD-10, history of excessive alcohol consumption with code 307 or 322 in ICD-7, 291 or 303 in ICD-9 and ICD-8, and F10 in ICD-10, or vitamin-B deficiency associated with alcohol with codes 280-281 in ICD-7, 261.00-262.00 in ICD-8, 265 in ICD-9, or E51-52 G62.1 in ICD-10).

All tests were two-sided with the significance level of 0.05 . Analyses were performed using SAS Statistical Package (version 9.0, SAS Institute Inc., Gary, NC, USA).

\section{RESULTS}

\section{Study participants}

During the follow-up of all women in the study cohort, 115 cases of EA, 246 cases of EJA, and 363 cases of SCC were identified. The corresponding numbers of male cases were 890, 1116, and 917, respectively. The numbers of controls were 10 times the number in each case group (Table 1 ). The average age at diagnosis in women was 59,55 , and 58 years for EA, EJA, and SCC, respectively. The corresponding ages in men were 59,56, and 58 years for EA, EJA, and SCC, respectively. Some characteristics of the cases and controls are presented in Table 1. Both female and male cases had, in general, a shorter education. The frequency of people with no children was higher in the controls groups compared with each of the case groups.

\section{Reproductive factors and risk of EA}

As presented in Table 2, parous women were at a possibly decreased risk of EA compared with non-parous women, but there was no statistically significant effect $(\mathrm{OR}=0.66,95 \% \mathrm{CI} 0.38-1.14)$. A decreased risk was also indicated among women with three or more children compared with women with one child, but it was not statistically significant $(\mathrm{OR}=0.81,95 \% \mathrm{CI} 0.44-1.50)$. Older age at first birth suggested an increased risk compared with younger age, but it was not statistically significant $(\mathrm{OR}=1.33,95 \% \mathrm{CI}$ $0.57-3.13)$. In analyses restricted to women aged at least 50 years, similar results were found (Table 3 ).

Men who had children were at a decreased risk of EA compared with men without children $(\mathrm{OR}=0.76,95 \%$ CI $0.65-0.90)$. However, the number of children did not influence the risk (Table 2). Unlike women, men having their first child at ages over 
Table I Characteristics of cases of EA or/and EJA, SCC of the oesophagus, and controls in women and men in Sweden, 1932-2008

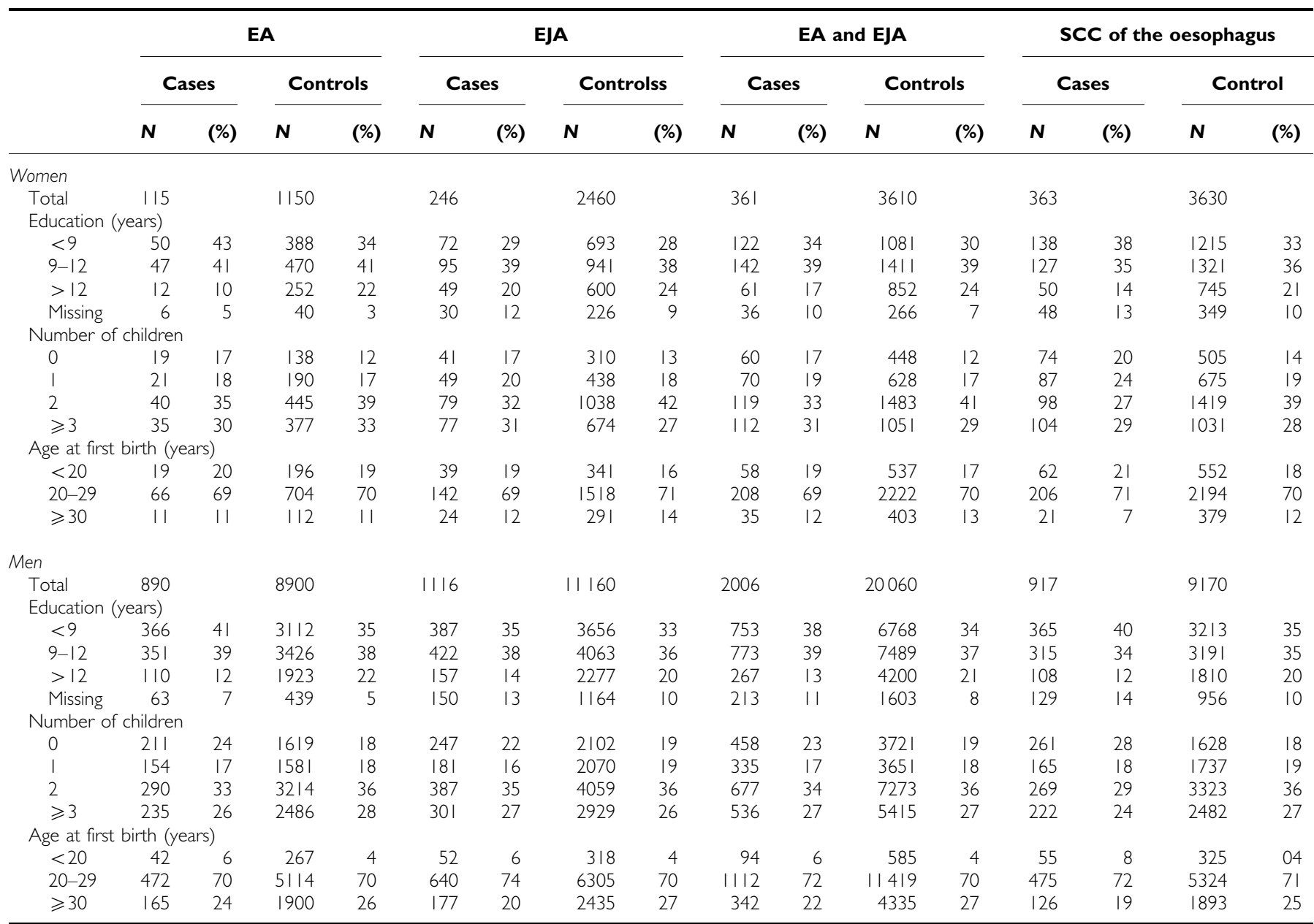

Abbreviations: EA = oesophageal adenocarcinoma; EJA = gastroesophageal junctional adenocarcinoma; SCC = squamous cell carcinoma.

30 years were at a decreased risk compared with men aged younger than 20 years $(\mathrm{OR}=0.64,95 \%$ CI $0.44-0.93)$, but no dose-response risk was found ( $P$-value for trend $=0.34$, Table 2 ).

\section{Reproductive factors and risk of EJA}

A possibly decreased risk EJA was found for parous women compared with non-parous women $(\mathrm{OR}=0.76,95 \%$ CI $0.52-1.11)$. Women with three or more children were at a similar risk compared with women with one child $(\mathrm{OR}=0.97,95 \% \mathrm{CI}$ 0.65-1.46). Older age at first birth indicated a decreased risk (Table 2). When the analyses were restricted to women aged at least 50 years, similar results were found (Table 3 ).

Men with at least one child were at a decreased risk EJA compared with men without children $(\mathrm{OR}=0.86,95 \% \mathrm{CI}$ 0.74-1.00), but no such association was found for those who reported to have more than one child (Table 2). Older age at first birth in men was followed by a decreased risk ( $P$-value for trend $<0.01$ ).

\section{Reproductive factors and risk of EA and EJA}

When combining EA and EJA, parous women were at a significantly decreased risk compared with non-parous women $(\mathrm{OR}=0.73,95 \%$ CI 0 53-0.99). There was no further reduction in risk in women who had given birth to at least three children compared with those with one child ( $\mathrm{OR}=0.93,95 \%$ CI $0.67-1.30)$.
Age at first birth did not influence the risk in women (Table 2). In analyses restricted to women aged at least 50 years, similar results were found (Table 3 ).

In men, the results were similar, exceptfor a decreased risk of EA and EJA with older age $(P$ for trend $<0.01)$.

\section{Reproductive factors and risk of SCC}

Women with at least one child showed a decreased risk of SCC compared with women with no children $(\mathrm{OR}=0.65,95 \% \mathrm{CI}$ 0.48-0.88), but there were no trends for more than one child $(P=0.25)$ or for age at first birth $(P=0.15)$. When the analyses were restricted to women aged at least 50 years, similar results were found (Table 3 ).

Similar results were observed in men with children compared with men with no children, and in men with more than one child (Table 2). Older age at first birth indicated a decreased risk of SCC $(P$-value for trend $=0.03)$.

\section{DISCUSSION}

This study indicated that childlessness is followed by an increased risk of EA and EJA, whereas the results of having more than one child and age at first delivery were contradictory, regarding the hypotheses of the effects of sex hormone. The results were similar in men and also the risk estimates for SCC were similar. 
Table 2 OR and 95\% Cl for association among parity, age at first birth, and risk of EA or/and EJA, SCC of the oesophagus in women and men in Sweden, 1932-2008

\begin{tabular}{|c|c|c|c|c|}
\hline & $\begin{array}{c}\text { EA } \\
\text { OR }(95 \% \mathrm{CI})\end{array}$ & $\begin{array}{c}\text { EJA } \\
\text { OR }(95 \% \mathrm{Cl})\end{array}$ & $\begin{array}{l}\text { EA and EJA } \\
\text { OR }(95 \% \mathrm{Cl})\end{array}$ & $\begin{array}{c}\text { SCC of the oesophagus } \\
\text { OR }(95 \% \mathrm{Cl})\end{array}$ \\
\hline \multicolumn{5}{|l|}{ Women } \\
\hline Non-parous & I.00 (Reference) & I.00 (Reference) & I.00 (Reference) & I.00 (Reference) \\
\hline Parous & $0.66(0.38-1.14)$ & $0.76(0.52-1.11)$ & $0.73(0.53-0.99)$ & $0.65(0.48-0.88)$ \\
\hline \multicolumn{5}{|l|}{ Number of children ${ }^{a, c}$} \\
\hline 1 & 1.00 (Reference) & 1.00 (Reference) & 1.00 (Reference) & 1.00 (Reference) \\
\hline$P$-value for trend & 0.43 & 0.54 & 0.94 & 0.25 \\
\hline \multicolumn{5}{|c|}{ Age at first birth (years) ${ }^{a, c}$} \\
\hline$<20$ & I.00 (Reference) & I.00 (Reference) & I.00 (Reference) & I.00 (Reference) \\
\hline $20-29$ & $1.13(0.64-1.99)$ & $0.92(0.63-1.36)$ & $0.99(0.73-1.37)$ & $1.05(0.75-1.45)$ \\
\hline$\geqslant 30$ & $1.33(0.57-3.13)$ & $0.80(0.45-1.42)$ & $0.95(0.59-1.53)$ & $0.61(0.35-1.07)$ \\
\hline$P$-value for trend & 0.42 & 0.32 & 0.71 & 0.15 \\
\hline \multicolumn{5}{|l|}{ Men } \\
\hline \multicolumn{5}{|l|}{ Number of children ${ }^{\mathrm{a}, \mathrm{c}}$} \\
\hline I & I.00 (Reference) & 1.00 (Reference) & 1.00 (Reference) & 1.00 (Reference) \\
\hline 2 & $0.97(0.78-1.20)$ & $1.04(0.86-1.25)$ & $1.01(0.87-1.16)$ & $0.91(0.74-1.13)$ \\
\hline$\geqslant 3$ & $0.92(0.74-1.16)$ & $1.04(0.85-1.27)$ & $0.99(0.85-1.15)$ & $0.90(0.7 \mid-1.13)$ \\
\hline$P$-value for trend & 0.75 & 0.69 & 0.60 & 0.21 \\
\hline \multicolumn{5}{|c|}{ Age at first birth (years) ${ }^{a, c}$} \\
\hline$<20$ & I.00 (Reference) & I.00 (Reference) & I.00 (Reference) & I.00 (Reference) \\
\hline $20-29$ & $0.65(0.46-0.91)$ & $0.66(0.49-0.90)$ & $0.65(0.52-0.82)$ & $0.70(0.51-0.98)$ \\
\hline$\geqslant 30$ & $0.64(0.44-0.93)$ & $0.49(0.35-0.69)$ & $0.55(0.43-0.7 \mid)$ & $0.60(0.4 I-0.87)$ \\
\hline$P$-value for trend & 0.34 & $<0.01$ & $<0.01$ & 0.03 \\
\hline
\end{tabular}

Abbreviations: $\mathrm{Cl}=$ confidence interval; $\mathrm{EA}=$ oesophageal adenocarcinoma; $\mathrm{EJ} \mathrm{A}=$ gastroesophageal junctional adenocarcinoma; $\mathrm{OR}=\mathrm{odds}$ ratio; $\mathrm{SCC}=$ squamous cell carcinoma. ${ }^{\mathrm{a}} \mathrm{ORs}$ were estimated from conditional logistic regression models, conditioned on age and sex, and adjusted for education, diabetes, obesity, tobacco smoking and

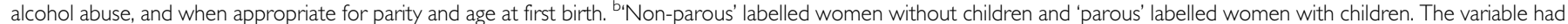
the same categories for men but was named as 'no children' and 'has children'. 'Men or women have children.

Strengths of the present study include the nation-wide, population-based design, large sample size, complete and longterm follow-up, and high validity of Swedish register data. Furthermore, the use of men for comparison made it possible to differentiate between sex hormonal exposure effects and confounding effects. However, a limitation was the inability to control for some specific potential confounders, that is, age at menarche and menopause, use of oral contraceptives, hormone replacement therapy (HRT), non-steroidal anti-inflammatory drugs, and dietary factors. Although there is a possibility to retrieve data on oral contraceptives and hormone replacement therapy from the Swedish Prescription Register, this registry was initiated only in July 2005, leaving a too short follow-up time to include enough number of cases, especially female cases. Moreover, education, place of residence, and diagnoses related to some other potential confounding factors were considered, that is, diabetes, obesity, tobacco smoking, and alcohol abuse. Selection and information biases were not an issue, as the study was nested within a well-defined cohort, and the exposure information was recorded independent of the outcome. Information on stillbirths was not available, but stillbirths constitute only a small proportion of all births in Sweden with a rate of $1.7 \%$ in 1955 that decreased to $0.4 \%$ in 1985 (2000).

The rarity of female cases of EA and EJA has prohibited studies addressing the association with reproductive factors. And the few available studies have provided inconsistent results. Compared with the present study, previous studies included substantially fewer female cases of EA, except a recent cohort study from the United Kingdom (Green et al, 2012b). Briefly, a case-control study from the United Kingdom, including 74 cases of EA, reported a statistically non-significant protective effect of having three or more children compared with no children $(\mathrm{OR}=0.69$, 95\% CI 0.23-2.01). In the Women's Health Initiative clinical trials from the United States, which identified 23 EA and 34 SCC in post-menopausal women, non-significant results were observed (Bodelon et al, 2011). A pooled analysis including cases from Ireland, the United Kingdom, the United States, and Australia suggested that lower parity might be related to a higher risk of EA and EJA, but the results were not statistically significant (CroninFenton et al, 2010). Our group conducted a case-control study of 63 female cases of EA and EJA in which no associations with parity or age at delivery were identified (Lagergren et al, 2005). The National Institutes of Health of the United States of the American Association of Retired Persons (NIH AARP diet and Health cohort) identified $25 \mathrm{EA}$ and found a potentially decreased risk of high parity and older age at first birth, although not statistically significant (Freedman et al, 2010). However, similar results were observed for SCC, and they did not study the association in men (Freedman et al, 2010). Our study regarding parity is consistent with results from the Million Women Study Cohort conducted in United Kingdom, which included substantial female oesophageal cancer cases (Green et al, 2012b). Both studies found a protective association of parous women compared with non-parous women, although the role of age at first birth were not clear in the both studies. Furthermore, the evidence from men in our study indicated the possible confounding factors other than sex hormones. The previous results combined with the results of the present study do not strongly support association between reproductive factors and the risk of EA. 
Table 3 OR and 95\% Cl for association among parity, age at first birth, and risk of EA orland EJA, SCC of the oesophagus in women and men aged equal or older than 50 years, Sweden, 1932-2008

\begin{tabular}{|c|c|c|c|c|}
\hline & $\begin{array}{c}\text { EA } \\
\geqslant 50 \\
\text { OR }(95 \% \mathrm{CI})\end{array}$ & $\begin{array}{c}\text { EJA } \\
\geqslant 50 \\
\text { OR }(95 \% \mathrm{CI})\end{array}$ & $\begin{array}{c}\text { EA and EJA } \\
\quad \geqslant 50 \\
\text { OR }(\mathbf{9 5} \% \mathrm{CI})\end{array}$ & $\begin{array}{c}\text { SCC of the oesophagus } \\
\geqslant 50 \\
\text { OR }(95 \% \mathrm{CI})\end{array}$ \\
\hline \multicolumn{5}{|l|}{ Women } \\
\hline \multicolumn{5}{|l|}{ Parity ${ }^{a, b}$} \\
\hline Non-parous & I.00 (Reference) & I.00 (Reference) & I.00 (Reference) & I.00 (Reference) \\
\hline Parous & $0.66(0.37-1.17)$ & $0.69(0.45-1.06)$ & $0.67(0.47-0.94)$ & $0.68(0.50-0.94)$ \\
\hline \multicolumn{5}{|l|}{ Number of children ${ }^{\mathrm{a}, \mathrm{c}}$} \\
\hline I & I.00 (Reference) & I.00 (Reference) & I.00 (Reference) & I.00 (Reference) \\
\hline 2 & $0.81(0.45-1.49)$ & $0.75(0.47-1.20)$ & $0.77(0.53-1.11)$ & $0.53(0.38-0.75)$ \\
\hline$\geqslant 3$ & $0.72(0.38-1.38)$ & $1.21(0.75-1.96)$ & $1.01(0.69-1.49)$ & $0.68(0.48-0.98)$ \\
\hline$P$-value for trend & 0.30 & 0.26 & 0.80 & 0.19 \\
\hline \multicolumn{5}{|c|}{ Age at first birth (years) ${ }^{a, c}$} \\
\hline$<20$ & I.00 (Reference) & I.00 (Reference) & I.00 (Reference) & I.00 (Reference) \\
\hline $20-29$ & I.II (0.60-2.03) & $0.83(0.53-1.30)$ & $0.94(0.66-1.35)$ & $0.99(0.69-1.40)$ \\
\hline$\geqslant 30$ & 1.01 (0.39-2.65) & $0.80(0.4 \mid-1.60)$ & $0.89(0.5|-| .55)$ & $0.54(0.29-1.00)$ \\
\hline$P$-value for trend & 0.90 & 0.37 & 0.53 & 0.10 \\
\hline \multicolumn{5}{|l|}{ Men } \\
\hline \multicolumn{5}{|l|}{ Parity ${ }^{a, b}$} \\
\hline No children & I.00 (Reference) & I.00 (Reference) & I.00 (Reference) & I.00 (Reference) \\
\hline Has children & $0.77(0.64-0.93)$ & $0.92(0.76-1.10)$ & $0.84(0.74-0.96)$ & $0.61(0.52-0.72)$ \\
\hline \multicolumn{5}{|l|}{ Number of children ${ }^{a, c}$} \\
\hline I & I.00 (Reference) & I.00 (Reference) & I.00 (Reference) & I.00 (Reference) \\
\hline 2 & $1.05(0.83-1.32)$ & $1.10(0.89-1.36)$ & $1.07(0.92-1.25)$ & $0.99(0.78-1.24)$ \\
\hline$\geqslant 3$ & $0.99(0.78-1.27)$ & $1.09(0.86-1.37)$ & $1.04(0.88-1.23)$ & $0.91(0.71-1.17)$ \\
\hline$P$-value for trend & 0.96 & 0.78 & 0.86 & 0.24 \\
\hline \multicolumn{5}{|c|}{ Age at first birth (years) ${ }^{a, c}$} \\
\hline$<20$ & I.00 (Reference) & I.00 (Reference) & I.00 (Reference) & I.00 (Reference) \\
\hline $20-29$ & $0.65(0.45-0.95)$ & $0.76(0.53-1.10)$ & $0.7 \mid(0.55-0.92)$ & $0.66(0.46-0.93)$ \\
\hline$\geqslant 30$ & $0.66(0.44-1.00)$ & $0.57(0.38-0.85)$ & $0.61(0.46-0.82)$ & $0.55(0.37-0.82)$ \\
\hline$P$-value for trend & 0.48 & 0.01 & $<0.01$ & 0.01 \\
\hline
\end{tabular}

Abbreviations: $\mathrm{Cl}=$ confidence interval; $\mathrm{EA}=$ oesophageal adenocarcinoma; $\mathrm{EJA}=$ gastroesophageal junctional adenocarcinoma; $\mathrm{OR}=\mathrm{odds}$ ratio; $\mathrm{SCC}=$ squamous cell carcinoma. ${ }^{a}$ ORs were estimated from conditional logistic regression models, conditioned on age and sex, and adjusted for education, diabetes, obesity, tobacco smoking, and alcohol abuse, and when appropriate for parity and age at first birth. 'Non-parous' labelled women without children and 'parous' labelled women with children. The variable had the same categories for men but was named as 'no children' and 'has children'. 'Men or women have children.

Other reproductive factors, that is, age at menarche, age at menopause, surgery with excision of genital organs, and breastfeeding, have also been studied in relation to risk of EA and EJA in women, although most of them did not reveal significant associations (Cronin-Fenton et al, 2010; Freedman et al, 2010; Bodelon et al, 2011). An exception is a decreased risk of these tumours related to an increased level of breastfeeding among women, which was first suggested in a case-control study from the United Kingdom (Cheng et al, 2000), and later confirmed in a pooled analysis of large population-based case-control studies (Cronin-Fenton et al, 2010). Exogenous hormone replacement treatment does not seem to substantially influence the risk of EA (Lofdahl et al, 2008; Bodelon et al, 2011); however, a nested casecontrol study from the United Kingdom recently identified a significant reduced risk of oesophageal cancer in women who prescribed hormone therapy. Our study restricted the analysis to women or men aged equal or older than 50 years, as the hypothesis is that endogenous hormone levels would fall at the time of menopause (Rannevik et al, 1995), and hormone therapy might involve supplementation with exogenous oestrogens. As there were too few cases of pre-menopause in this study, we only included a sub-analysis for the hypothetical post-menopausal population (age $\geqslant 50$ years). The results of this subgroup were similar as in the overall analysis.

The finding of similar effects of reproductive factors in women and men on risk of EA or EJA in the present study highlights the possibility of confounding by non-hormonal exposures. In addition, the similar effects comparing adenocarcinomas with
SCC suggest an influence of confounding rather than causality. Several factors unrelated to sex hormones might explain the inverse association between parity and these tumours, for example, education, socio-economic status, culture, religion, diet, and other lifestyle habits. Older age at first birth, for example, would be related to higher education level, which might explain the similar risk patterns in women and men in this study. Moreover, people with children might smoke less, use less alcohol, or lead a generally healthier life than those without children. In addition, women with a higher education level or socio-economic status would use hormone replacement treatment more often.

In conclusion, this large and population-based study suggests that reproductive factors are associated with risk of EA or EJA, but the similar findings in women and men, and the similar results in patients with SCC could not rule out factors other than sex hormones that explain these associations. However, the lack of information of age at menarche/menopause and HRT use in the present study could not counteract the hormonal hypothesis completely.

\section{ACKNOWLEDGEMENTS}

This work was funded by SIMSAM (the Swedish Initiative for Research on Microdata in the Social and Medical Sciences) from the Swedish Research Council. The Swedish Research Council had no role in study design, data collection and analysis, decision to publish, or preparation of the manuscript. 


\section{REFERENCES}

Barlow L, Westergren K, Holmberg L, Talback M (2008) The completeness of the Swedish Cancer Register - a sample survey for year 1998. Acta Oncol 48(1): 27-33

Blot WJ, Devesa SS, Kneller RW, Fraumeni Jr JF (1991) Rising incidence of adenocarcinoma of the esophagus and gastric cardia. JAMA 265(10): 1287-1289

Bodelon C, Anderson GL, Rossing MA, Chlebowski RT, Ochs-Balcom HM, Vaughan TL (2011) Hormonal factors and risks of esophageal squamous cell carcinoma and adenocarcinoma in postmenopausal women. Cancer Prev Res (Phila) 4(6): 840-850

Botterweck AA, Schouten LJ, Volovics A, Dorant E, van Den Brandt PA (2000) Trends in incidence of adenocarcinoma of the oesophagus and gastric cardia in ten European countries. Int $J$ Epidemiol 29(4): 645-654

Castellsague X, Munoz N, De Stefani E, Victora CG, Castelletto R, Rolon PA, Quintana MJ (1999) Independent and joint effects of tobacco smoking and alcohol drinking on the risk of esophageal cancer in men and women. Int J Cancer 82(5): 657-664

Cheng KK, Sharp L, McKinney PA, Logan RF, Chilvers CE, Cook-Mozaffari P, Ahmed A, Day NE (2000) A case-control study of oesophageal adenocarcinoma in women: a preventable disease. Br J Cancer 83(1): 127-132

Cook MB, Chow WH, Devesa SS (2009) Oesophageal cancer incidence in the United States by race, sex, and histologic type, 1977-2005. Br J Cancer 101(5): 855-859

Cronin-Fenton DP, Murray LJ, Whiteman DC, Cardwell C, Webb PM, Jordan SJ, Corley DA, Sharp L, Lagergren J (2010) Reproductive and sex hormonal factors and oesophageal and gastric junction adenocarcinoma: a pooled analysis. Eur J Cancer 46(11): 2067-2076

Freedman ND, Lacey Jr JV, Hollenbeck AR, Leitzmann MF, Schatzkin A, Abnet CC (2010) The association of menstrual and reproductive factors with upper gastrointestinal tract cancers in the NIH-AARP cohort. Cancer 116(6): 1572-1581

Gold EB, Bromberger J, Crawford S, Samuels S, Greendale GA, Harlow SD, Harlow SD, Skurnick J (2001) Factors associated with age at natural menopause in a multiethnic sample of midlife women. Am J Epidemiol 153(9): 865-874

Green J, Czanner G, Reeves G, Watson J, Wise L, Roddam A, Roddam A, Beral V (2012a) Menopausal hormone therapy and risk of gastrointestinal cancer: nested case-control study within a prospective cohort, and metaanalysis. Int J Cancer 130(10): 2387-2396
Green J, Roddam A, Pirie K, Kirichek O, Reeves G, Beral V (2012b) Reproductive factors and risk of oesophageal and gastric cancer in the Million Women Study cohort. Br J Cancer 106(1): 210-216

Hankinson SE, Colditz GA, Hunter DJ, Manson JE, Willett WC, Stampfer MJ, Stampfer MJ, Longcope C, Speizer FE (1995) Reproductive factors and family history of breast cancer in relation to plasma estrogen and prolactin levels in postmenopausal women in the Nurses' Health Study (United States). Cancer Causes Control 6(3): 217-224

Lagergren J, Jansson C (2005) Sex hormones and oesophageal adenocarcinoma: influence of childbearing? Br J Cancer 93(8): 859-861

Lagergren J, Nyren O (1998) Do sex hormones play a role in the etiology of esophageal adenocarcinoma? A new hypothesis tested in a populationbased cohort of prostate cancer patients. Cancer Epidemiol Biomarkers Prev 7(10): 913-915

Lepage C, Rachet B, Jooste V, Faivre J, Coleman MP (2008) Continuing rapid increase in esophageal adenocarcinoma in England and Wales. Am J Gastroenterol 103(11): 2694-2699

Lindblad M, Ye W, Lindgren A, Lagergren J (2006) Disparities in the classification of esophageal and cardia adenocarcinomas and their influence on reported incidence rates. Ann Surg 243(4): 479-485

Lofdahl HE, Lu Y, Lagergren J (2008) Sex-specific risk factor profile in oesophageal adenocarcinoma. Br J Cancer 99(9): 1506-1510

McKnight B, Cook LS, Weiss NS (1999) Logistic regression analysis for more than one characteristic of exposure. Am J Epidemiol 149(11): 984-992

National Board of Health and Welfare (2000) Yearbook of Health and Medical Care (edn). National Board of Health and Welfare: Stockholm

Rannevik G, Jeppsson S, Johnell O, Bjerre B, Laurell-Borulf Y, Svanberg L (1995) A longitudinal study of the perimenopausal transition: altered profiles of steroid and pituitary hormones, SHBG and bone mineral density. Maturitas 21(2): 103-113

Rodstrom K, Bengtsson C, Milsom I, Lissner L, Sundh V, Bjourkelund C (2003) Evidence for a secular trend in menopausal age: a population study of women in Gothenburg. Menopause 10(6): 538-543

Voutilainen M (2008) Epidemiological trends in oesophageal cancer in the Nordic countries. Scand J Gastroenterol 43(3): 323-327

Whiteman DC, Sadeghi S, Pandeya N, Smithers BM, Gotley DC, Bain CJ, Webb PM, Green AC, Australian Cancer Study (2008) Combined effects of obesity, acid reflux and smoking on the risk of adenocarcinomas of the oesophagus. Gut 57(2): 173-180

This work is published under the standard license to publish agreement. After 12 months the work will become freely available and the license terms will switch to a Creative Commons Attribution-NonCommercial-Share Alike 3.0 Unported License. 